\title{
Comment on Zeng et al.: Vascularised greater trochanter bone graft, combined free iliac flap and impaction bone grafting for osteonecrosis of the femoral head
}

\author{
Vipul Vijay • Vineet Tyagi • Anil Mehtani
}

Received: 7 April 2013 / Accepted: 24 April 2013 /Published online: 12 May 2013

(C) Springer-Verlag Berlin Heidelberg 2013

\section{Dear Editor,}

We read with great interest the article by Zeng et al. [1] on the management of osteonecrosis of the femoral head by a novel approach using the greater trochanter flap and combined free iliac crest flap, and their work should be praised.

The management, as proposed by the authors, uses the flap based on the lateral circumflex femoral artery along with impaction grafting. After reading the article though, we have the following queries:

1. The authors describe results of 58 cases with 64 hips treated with the procedure but they have not mentioned the aetiologies of the avascular necrosis in the treated hips. As very rightly pointed out by the authors in their discussion, Korompilias et al. [2] have correlated the results of hip preservation surgery with the pathology of AVN. Baksi et al. [3] also reported good results in idiopathic and steroidinduced AVN as compared to post traumatic osteonecrosis which was associated with delayed recovery and healing. Details about the aetiologies of the treated hips in this study may thus affect outcome.

2. Baksi et al. [3] reported their results of muscle pedicle graft in 187 femoral heads with average 16.5 years follow up and suggested the patients deemed good candidates for hip preservation surgery should have preservation of range of motion at least in one plane, especially flexion. Did the authors use any such inclusion or exclusion criteria?

V. Vijay $(\bowtie) \cdot$ V. Tyagi $\cdot$ A. Mehtani

Department of Orthopaedics, Lady Hardinge Medical College,

New Delhi, India

e-mail: dr_vipulvijay@yahoo.com
3. All the patients included in the study belong to ARCO stage III. Such patients mostly have some associated deformities in the hip joint due to the disease process. Baksi et al. [3] managed these deformities with adductor tenotomies and traction. The authors have not mentioned whether they required any soft tissue release along with the bony procedure and post-operative traction as such releases would also greatly improve the post-operative clinical results.

4. The method of fixation of the greater trochanter flap should be described in more detail. The muscle pedicle graft by Baksi et al. and Meyer et al. [4] was fixed in a trough made in the femoral neck but here the authors describe putting the greater trochanter flap in the cartilage defect created in the head.

We agree with the authors that the sample size was small and the group needs to be followed up for a longer period to know the final results of this excellent novel procedure for head preservation in osteonecrosis of the head of the femur.

We thank the authors for their invaluable work.

\section{References}

1. Zeng YR, He S, Feng WJ et al (2013) Vascularised greater trochanter bone graft, combined free iliac flap and impaction bone grafting for osteonecrosis of the femoral head. Int Orthop 37(3):391-398

2. Korompilias AV, Lykissas MG, Beris AE et al (2009) Vascularised fibular graft in the management of femoral head osteonecrosis: twenty years later. J Bone Joint Surg Br 91(3):287-293

3. Baksi DP, Pal AK, Baksi DD (2009) Long-term results of decompression and muscle-pedicle bone grafting for osteonecrosis of the femoral head. Int Orthop 33(1):41-47

4. Meyers MH (1978) The treatment of osteonecrosis of the hip with fresh osteochondral allografts and with the muscle pedicle graft technique. Clin Orthop 130:202-209 